\title{
VISI PROFETIK HAJI: STRATEGI KEBUDAYAAN DALAM TRANSFORMASI SOSIAL
}

\author{
Suwito NS \\ STAIN Purwokerto \\ J1. A. Yani 40 A Telp (+62-281) 635624 Purwokerto 53126 \\ E-mail: suwitons@gmail.com \\ HP. +62-8122739120
}

Abstract: This article describe and analyze the prophetic vision of hajj in Ali Syari'ati perspective. The analysis applies social approach as stated by Kuntowijoyo as prophetic social science. There are three aims on prophetic social, humanism, liberation and transcendence. This article shows that hajj does not only make people closer to the God but also teach them to be more sensitive to the environment. There are three essential meanings, humanism, liberalism and transcendence.

Abstrak: Artikel ini mencoba mendeskripsikan dan menganalisis visi profetik haji Ali Syari'ati. Kajian ini menggunakan pendekatan ilmu sosial sebagaimana dikemukakan oleh Kuntowijoyo sebagai ilmu sosial profetik. Ada tiga pilar tujuan ilmu sosial profetik, yakni humanisasi, liberasi, dan transendensi. Artikel ini menunjukkan bahwa haji tidak sekadar ibadah yang mengarahkan seorang hamba lebih dekat pada Tuhannya saja. Namun, ibadah haji adalah mendidik manusia agar peka terhadap lingkungan sekitarnya. Artinya, haji memiliki tiga makna kesekaligusan, yaitu humanisasi yang tampak sejak mengenakan ihrām. Dalam ihrām jamaah juga dididik untuk melakukan liberasi dan transendensi. Demikian juga pada rukun atau segment ibadah haji lainnya juga memiliki semangat profetik dengan merelasikan tiga komponen penting.

Kata Kunci: Profetik, haji, wukuf, ihrām, Mina.

\section{A. Pendahuluan}

Sebuah sinetron di stasiun TV swasta akhir-akhir ini, tentang tokoh Haji Mukidin banyak diperbincangkan orang. Perilaku seorang muslim yang telah dua kali haji memancing orang lain di sekelilingnya berkomentar minor. Haji ibadah rangkaian ibadah mahḍah, pilar Islam yang lima sebagaimana hadis 
tentang lima hal yang menjadi dasar Islam, yakni syahadat, shalat, zakat, puasa, dan haji (al-Bukhāri, TT: 12).

Sebagaimana ibadah lain, haji memiliki selain dimensi ritual yang bernuansa transenden, juga memiliki spirit perubahan (pembebasan sosial). Ibadah ini dominan dan kental dengan nuansa profetik. Yakni, fungsi ganda antara ibadah vertikal maupun horizontal, baik aspek transendensi dan humanisasi dan liberasi. Namun, ibadah ini justru belum dipahami sebagai sebagai motor penggerak perubahan masyarakat juga belum dipahami sebagai kegiatan napak tilas kenabian yang komprehensif dari ibadah yang disyariatkan.

Ali Syari'ati, pemikir Islam modern mencoba memaknai ibadah haji melalui pendekatan sosiologis. Haji baginya adalah pelajaran yang tidak dikatakan tetapi dilakukan (diamalkan). Amalannya bukan terbatas ritual saat melaksanakan haji, tetapi ritual itu hanya pemantik lahirnya kesadaran yang lebih besar terkait dengan hubungan seorang hamba dengan Tuhannya maupun dengan masyarakat di sekitarnya. Artikel ini mencoba menggali dan menganalisis pandangan Ali Syari'ati terkait dengan makna ibadah haji, khususnya pemaknaan ihram, wukuf, mabit di Muzdalifah, dan Mina dalam perubahan sosial yang terbingkai dalam diskursus profetik.

\section{B. Diskursus Profetik: Humanisme Teosentris}

Kata profetik berasal dari prophet (Inggris) berarti nabi. Dalam Oxford Dictionary, prophetic adalah (1) "of pertaining or proper to a prophet or prophecy", "having the character or funcition of a prophet", (2) "characterized by containing, or of the nature of prophecy, predictive". Makna profetik adalah mempunyai sifat atau ciri seperti nabi atau bersifat prediktif (Ahimsa-Putra, 2011: 5).

Istilah profetik (prophetic) berarti sifat kenabian yang di dalamnya terdapat sifat-sifat utama yang diinstalkan kepada seseorang yang dipilih Allah sebagai Nabi. Dalam konteks ini, kata profetik di dalamnya mencakup pandangan (visi) dan tugas (misi) kenabian dalam menjalankan tugasnya.

Diskurus ilmu sosial profetik muncul tahun 2000an, saat Kuntowijoyo menulis buku berjudul Paradigma Islam. Menurut Ahimsa-Putra (2011: 6) gagasan ini ditulis oleh Kuntowijoyo bahwa asal-usul pemikiran tersebut dapat ditemukan dalam tulisan-tulisan Muhammad Iqbal dan Roger Garaudy.

Sebagaimana dikatakan oleh Garaudy sebagaimana Ahimsa-Putra (2011: 8) bahwa sumber pengetahuan profetik adalah wahyu dan akal. Menurut Garaudy, bahwa Barat pernah terombang-ambing dengan hanya berdasar pada 
akal. Dengan demikian, al-Qur'an adalah sumber kebenaran dalam paradigma profetik melalui pendekatan strukturalis transendental.

Pendekatan strukturalis transendental dimaknai sebagai pengakuan adanya ide yang murni, yang bersumber dari luar diri manusia, suatu konstruk tentang struktur nilai yang berdiri sendiri dan bersifat transendetal (AhimsaPutra, 2011: 8).

Tujuan akhir yang ingin dicapai dari paradigma profetik adalah 1) humanisasi, 2) emansipasi, liberasi atau pembebasan, 3) transendensi. Hal ini dikatakan oleh Kuntowijoyo dengan mengutip Q.S.3:110. Tugas historis Islam adalah 1) menegakkan kebaikan, 2) mencegah kemungkaran, 3) beriman kepada Allah. Tiga muatan nilai inilah yang mengkarakterisasikan ilmu sosial profetik.

Paradigma ilmu sosial profetik bertumpu pada 1) humanisasi, 2) liberasi, dan 3) transendensi. Humanisasi artinya "memanusiakan manusia", "menghilangkan kebendaan" ketergant ungan, kekerasan, dan kebencian manusia. Ini merupakan implementasi amar ma'rüf, sementara liberasi adalah implementasi dari nahy munkar, sedangkan transendensi adalah implementasi dari tu'minūna billāh (Kuntowijoyo, 2003: 98).

Misi profetik dengan demikian adalah memperbaiki tatanan kehidupan dengan cara memanusiakan manusia, mengalamkan alam, serta menuhankan Tuhan. Dengan demikian, tugas profetik meletakkan dasar kehidupan sesuai dengan proporsinya. Menuhankan manusia adalah sebuah kekeliruan, demikian juga memanusiakan Tuhan adalah naif dan dzalim.

\section{Profil Ali Syari'ati}

Biografi Ali Syari'ati secara lengkap dapat ditemukan dalam bukunya Rahmena (1995: 205-257). Tulisan ini didasarkan pada beberapa sumber terutama pada Rahmena (1995: 205-257) Syari'ati lahir di Mazinan, 24 November 1933. Lahir dari keluarga taat beribadah. Ayahnya adalah seorang guru di sekolah dasar.

Sejak sekolah dasar di Ibn-e Yasin Primary School, dia telah rajin membaca buku-buku milik ayahnya hingga larut malam. Syari'ati kecil jarang bergaul dengan kawan sebayanya (Lihat Tim Penyusun, 1977: 106; Suwito NS, 2004: 54). Bahkan, saat di bangku SD, dia telah membaca karya-karya Victor Hugo yang telah diterjemahkan dalam Bahasa Persia.

Lulus SD, dia masuk di Firdowsi Secondary School dan lulus tahun 1950. Saat ini, dia mulai bersemangat belajar tentang filsafat dan tasawuf. Di samping 
itu, dia mulai senang dengan kajian kemanusiaan, baik yang berkaitan dengan seni berfikir dan teknik menjadi manusia. Ayahnyalah yang mengenalkan konsep kebebasan, kemerdekaan, harga diri, keluhuran budi, dan iman (Tasawassuli, 1992: 13-15; Azra, 1996: 76; Suwito NS, 2004: 55).

Akibat kebanyakan membaca tema-tema filsafat yang saling paradoks, Syari'ati sempat mengalami krisis kepribadian yang serius. Dia merasa pada jalan buntu filsafat yang serius. Kemelut dan krisis teratasi saat dia menemukan tulisan Rumi dalam Matsnawinya. Kata-kata Rumi menyelamatkannya dari kebuntuan filsafat (Suwito NS, 2004: 57).

Setelah dapat menyelesaikan problem ideologisnya, pada saat di Pendidikan Guru dia menemukan Islam sebagai medium epistemologis dalam melakukan perubahan sosial. Model yang dianut adalah gaya Abu Dzar alGhiffari. Dia adalah sosok sahabat Rasulullah yang komit dan sederhana.

Setelah lulus dari pendidikan guru, dia melanjutkan ke Sorbonne University di Paris, Perancis. Di Perancis dia belajar dari Louis Massignon, George Gurvich, Jaquer Berque, Jean Paul Satre, Alexis Carrel, dan lainnya. Dia lulus dari Sorbonne pada tahun 1963 dengan mempertahankan disertasi berjudul Les Merites de Balkh di bawah bimbingan Glibert Lazard.

Di antara karyanya adalah An Approach to Understanding Islam, A Glance at Tomorrow's History, A Waiting the Religion of Protest, Hajj, Eslamsenasi, Kevir, Man and Islam, Marxisme and Other Western Fallacies, An Islamic Critique, Mysticism: Equality and Freedom, On the Sociology in Islam, Relegion VS Religion, What to be Done? The Enlightened and Islamic Renaissance.

\section{Haji: Humanisasi, Liberasi, dan Transendensi}

Artikel ini membahas lima hal penting dalam haji, 1) iḥrām di miqāt, 2) wukuf di Arafah, 3) tawaf, 4) sai, 5) melempar jumrah.

\section{Iḥrām di Miqāt: Kesatuan Umat}

Bagi Syari'ati, haji adalah evolusi manusia menuju Allah. Dalam pelaksanaan haji, para hujjāj (jamaah haji) sebaiknya dapat mencapai pemahaman nilai filosofis yang terkadung di dalamnya. Dalam ibadah ini, secara komprehensif memuat nilai-nilai tentang konsep penciptaan, sejarah, tauhid, dan kesatuan umat (Syari'ati, 1983: 1).

Secara syar'i, haji dimulai dari miqāt (tempat batas awal pelaksanaan haji). Pada saat ini jamaah haji berkomitmen (niat) berhaji dengan pakaian ihram yang 
telah diatur secara tegas. Pakaian yang selama ini dipakai oleh jamaah harus diganti dengan pakaian kebesaran, yakni ihram.

Syari'ati memandang bahwa pakaian melambangkan status, perbedaan, dan strata. Pakaian juga menciptakan "batas" yang menyebabkan "perbedaan" dan perpecahan antar umat manusia. Sementara itu, perpecahan melahirkan diskriminasi. Dari sinilah muncul konsep tentang "aku" dan "kamu”, "kami”, dan "kalian" (Syari' ati, 1983: 11).

Arogansi sosial dari tingkat yang paling kecil hingga pada skup yang lebih besar muncul dapat muncul dari masalah "simbol" kostum ini. Mulai dari komunitas kecil seperti perusahaan kecil, institusi pemerintah, tingkat kesukuan, kebangsaan, bahkan pada tingkat negara. Diskriminasi pada kelompok lemah menjadi salah satu akibatnya.

"Kini lepaskan pakaianmu di miqāt, kenakan kain kafan, sehelai kain putih sederhana!". Dalam konteks ini, Syari'ati memandang bahwa simbol pakaian menyebabkan seseorang menjadi tinggi hati. Dengan ditanggalkannya pakaian yang melambangkan status tersebut, jamaah berlatih diri untuk rendah hati dan menghormati siapapun dan sadar akan kefanakan dan memahami eksistensinya (Syari'ati, 1983: 12).

Ihram adalah simbol kebersamaan dan menghindari perpecahan dan diskriminasi. Ihram adalah memberikan pembelajaran tent ang ikram (penghormatan) pada makhluk lain. Dengan berihram, jamaah dilatih menjadi manusia yang sebenarnya yang selalu bergerak menuju Allah (Q.S.24:42). Bergerak menuju Allah dengan cara menghilangkan sifat keakuan (egoisme) yang berlebihan.

Dalam konteks ini, Syari' ati menyitir beberapa ayat al-Qur'an unt uk memperkuat argumentasinya bahwa ihram adalah awal pergerakan kehidupan yang sebenarnya, yakni perjalanannya berevolusi menuju Allah (Syari'ati, 1983: 13).

Dalam rangka berevolusi menuju Allah, seorang anak manusia (ḥujjāj, jamaah haji) dilarang melakukan perbuatan-perbuat an yang merusak, seperti membunuh serangga, menebang atau mencabut pepohonan, berhubungan seksual, bertengkar, berdebat. Dalam konteks ini Q.S.2:197, menjelaskan bahwa orang yang haji dilarang a) rafats (berhubungan seks), b) fusūq (berbuat kerusakan), c) jidāl (perbedatan). Hal ini karena ketiga hal ini adalah simbol dominasi ego atau nafs.

Dalam tinjauan profetik, ritual ihram dalam ibadah haji sangat kental dengan unsur humanisasi, liberasi (pembebasan), dan transendensi sebagaimana 
dikatakan Kuntowijoyo (1994: 164). Islam dengan strategi kebudayaannya membebaskan manusia dari keterkungkungan budaya, yang di dalamnya termasuk aliran pikiran dan filsafat. Manusia diberikan derajat yang sangat mulia (akram) untuk membuat peradaban yang berbasis pada orientasi humanismeteosentris.

Islam, dalam hal ini telah menerapkan strategi kebudayaan dalam proses perubahan menuju masyarakat yang Islami. Dalam kacamata strategi kebudayaan, Islam menyampaikan pesan persamaan derajat melalui simbol pelepasan baju yang secara sosio-antropologis melambangkan perbedaan dan menimbulkan diskriminasi.

Dalam kajian tasawuf, iḥrām dapat dipandang sebagai ḥāl (keadaan jiwa), sekaligus sebagai simbol dan identitas. Memang, ị̣rām hanya seringkali ị̣rām hanya dipahami dengan model pakaian. Tetapi, iḥrām adalah keadaan (ḥāl) juga memiliki pesan profetik liberasi yakni seseorang terbebas dari perbuatanperbuatan terlarang yang pernah disebut oleh malaikat dalam Q.S.2:30, yakni yufsidu (merusak) dan yasfik al-dimā', (membunuh) dalam bentuk apapun. Dari statement di atas, bukan berarti dalam keadaan di luar iḥrām seseorang tidak terlarang (boleh) melakukan kerusakan dan pembunuhan (Suwito NS, 2011: 93-94).

Selain pesan profetik liberasi, iḥrām memiliki pesan profetik transendensi sekaligus emansipasi yakni meleburnya sifat egoisme pada diri manusia yang dilebur dalam satu pola, yakni pola iḥrām. Iḥrām adalah pola Allah, yang di dalamnya memuat pesan kepatuhan, kesederhanaan, dan kebersamaan universal. Seseorang dalam posisi terlarang. Tidak boleh merusak, sekalipun hanya mematahkan ranting kecil dan merontokkan daun. Tidak boleh membunuh sekalipun seekor kutu yang sangat kecil (Suwito NS, 2011: 94).

Visi profetik haji dapat dilihat dari pandangan Syari'ati bahwa iḥrām adalah melepas keangkuhan dan ego yang lekat pada simbol baju. Syari'ati memandang bahwa baju melambangkan kekuasaan dan strata. Dalam keadaan ihram, semua ini ditanggalkan agar manusia sederajat. Manusia tampak sebagai manusia yang sama. Inilah humanisasi sekaligus liberasi. Saat memakai pakaian adat (baju non ị̣rām) simbol ego manusia menjadi lebih tampak. Dengan bajunya, mudah dikenali sebagai manajer atau staf, supir atau kondektur, eselon satu at au eselon empat, pejabat at au rakyat. I hrām meliberasikan membebaskan strata, golongan, dan kasta dalam masyarakat. Islam memandang sama manusia kecuali derajat ketapatuhannya kepada Allah. Dengan pemahaman yang benar dan komprehensi haji sangat potensial digunakan untuk penyadaran umat terkait dengan penemuan kasih sayang dari diri seseorang. 


\section{Arafah, Masy'ar (Muzdalifah), dan Mina}

Sesudah iḥrām, calon haji menuju ke satu tempat yang bernama 'Arāfah. Bagi Syari' ati yang penting di sini adalah "singgah" (Syari'ati, 1997: 59) atau dalam bahasa agamanya adalah "wukuf". Bagi Syari'ati proses menuju Arafah adalah proses inna lillāh (sesungguhnya kita adalah kepunyaan Allah, sedangkan kembali ke Kakbah adalah wa ilaihi rāji 'ūn (kepada-Nya kita akan kembali) (Syari'ati, 1997: 61).

Menurut Syari'ati perjalanan kembali kepada Allah terbagi menjadi tiga tahap yakni 1) Arafah, 2) Masy'ar, 3) Mina. Baginya, Arafah adalah "pengetahuan" dan "sain", sedangkan Masy'ar adalah "kesadaran" dan "pengertian", sedangkan Mina adalah "cinta" dan "keyakinan".

Proses kehidupan ini menunjukkan bahwa umat Islam diajari oleh Allah melalui ibadah haji bahwa ilmu pengetahuan dan sain amat penting bagi keperluan kemajuan manusia. Tahap Arafah mengisyaratkan pada jamaah haji untuk selalu menambah pengetahuan. Berhentilah (wukuflah) di Arafah. Pesan haji saat pada fase ini bermakna pelajarilah dan bacalah tanda-tanda alam agar kalian semua maju. Kenali dan kaitkan fenomenanya hingga menjadi teori. Bagi Syari'ati, puncak pengetahuan adalah ma'rifat yakni pengetahuan yang membimbing kedekatan dengan Allah (Syari'ati, 1997: 64).

Perjalanan berikutnya adalah tahap Masy'ar yakni tahap kesadaran, yakni kesadaran yang lahir dari pengetahuan. Bagi Syari'ati, Masy'ar adalah tahap kesadaran yang penuh tanggungjawab, kesucian, dan kesalehan. Dalam tahap ini, manusia tidak diperbolehkan melakukan dosa, penyelewengan, agresi, perkelahian, membunuh hewan sekecil apapun serta merusak tanaman. Ilmu melahirkan hikmah. Pemikiran yang berujung pada ditemukannya teori melahirkan tanggungjawab, dan inilah Masy'ar (Syari'ati, 1997: 73, 74).

Dalam konteks tasawuf, "laboratorium” 'Arāfah mengajari manusia tentang penegasian (nafi), pengosongan (takhalli), atau proses menguras jiwa dari sifat-sifat buruk (seperti merusak, membunuh, dan sifat destruktif lainnya). Di samping itu, 'Arāfah juga pembelajaran tentang penegasan (tatsbit) atau pengisian (taḥalli) sifat-sifat baik (seperti instrospeksi diri/muḥāsabah, menyesali masa lalu/tawbat, mendekatkan diri/muqārabah, tafakkur, dzikr, syukr, membaca ayat-ayat Allah baik qawliyyah/firman maupun kawniyah/alam semesta). Proses ini selaras dengan konsep fanā' wa baqā' sebagaimana disebut Abū Yazìid al-Bisțāmī (w. 874 M), jika perbuat an buruk sudah tidak ada maka yang ada (tersisa) hanyalah kebaikan (Aberry, 1993: 67-74).

Protes malaikat pada Q.S.2:30 dijawab oleh Allah dengan Q.S.5:95,96 tentang posisi dan keadaan iḥrām. Sebagaimana telah disebut di atas bahwa 
ihrām adalah proses "pengenolan" dari sifat-sifat buruk dan pengisian semangat kepatuhan total. Dari kedua sifat tersebut hati menjadi lembut dan pintupint unya terbuka untuk dapat menerima ilhām dan hidāyah (petunjuk), hal ini sebagaimana dalam Q.S.2:137; Q.S.3:20; Q.S.19:72; Q.S.47:17. "Laborat" 'Arāfah secara spiritual akan mengantarkan manusia pada kearifan universal, yakni 1) ma 'rifah pada Allah ( 'ārif bi Allāh), 2) ma'rifah (kenal) pada manusia dan kebutuhan-kebutuhannya ('ārif bi al-nās), dan 3) ma'rifah pada ekosistem dalam ekologi (alam semesta) 'ārif bi al-‘ālamin.

Kearifan pada Pencipta mendorong seseorang akan lebih taat padaNya dengan cara beribadah dalam kepatuhan yang sebenarnya. Yakni, patuh dan tunduk kepada al-Raḥmān dalam rangka mendapatkan keridhaan-Nya (rị̣an li al-Rahmān), dan sebaliknya berkonfrontasi dan beroposisi dengan setan (rajman li al-syayāțīn) ${ }^{1}$ sebagai kekuatan jahat baik dari dalam maupun dari luar (manusia dan jin). Kemudian kearifan pada manusia mendorong seseorang akan lebih menghargai keberadaan manusia sebagai makhluk terbaik Allah, ${ }^{2}$ serta kearifan pada lingkungan mendorong seseorang yang telah mendapatkan training dan mengambil pelajaran training ini akan ramah terhadap lingkungan dengan cara mengambil peran terhadap penyelamatan alam sekitar.

Dari uraian di atas dapat ditarik kesimpulan bahwa 'Arāfah adalah kondisi spiritual dan simbol spiritual bagi perjalanan manusia tujuan puncaknya adalah ma'rifah. 'Arāfah pada saat musim haji hanyalah laborat pemantik kesadaran dan kualitas spiritual. Pesan 'Arāfah yang sebenarnya adalah lahirnya kesadaran akan 1) patuh dan tunduk pada Allah, 2) ramah kepada manusia, 3) ramah terhadap lingkungan dalam arti yang sebenar-benarnya. Ketiga hal tersebut terimplementasi pada diri seseorang sepanjang hayat di mana pun seseorang tersebut berada. Inilah profetik dari haji, yakni transendensi, liberasi, dan emansipasi sebagaimana dikatakan Kuntowijoyo.

Dengan kata lain, maqām 'Arafah adalah wujud konkret dari relasi berbasis rahmat (kasih sayang), yakni relasi yang berbasis pada hubungan segitiga (Allah, manusia, dan alam). Paradigma antropo-sentris saja tidak cukup untuk memahami model relasi ini. Antropo-sentris lebih menekankan pada kepuasan diri, atau dengan istilah lain cinta berbasis egoisme diri. Cinta yang berbasis pada diri akan mengakibatkan penafian keberadaan selain dirinya sendiri. Jika ini terjadi, menggejala, dan massif, maka kerusakan akan terjadi.

\footnotetext{
${ }^{1}$ Sebuah doa yang seringkali dibaca oleh hujjāj saat melempar jumrah, yakni rajman li alshayātīin wa riḍan li al-Raḥmān, yang arti bebasnya adalah berposisi dengan setan dan rela berkoalisi dengan Dzat Yang Maha Pengasih.

${ }^{2}$ Q.S. 17: 70, Q.S. 95: 4.
} 
Dalam konteks ini, seseorang telah mengalami proses transformasi jika terdapat kesadaran akan relasi yang berbasis rạ̣mah (kasih sayang) dalam kaca mata hubungan segitiga. Kesadaran ini akan melahirkan kepatuhan ego untuk bertransformasi dari 'abd Allāh yang sifatnya saleh secara individu/parsial menuju khalīfah Allāh (saleh komunal/integral). Pembahasan tentang transformasi ini secara spesifik akan dibahas pada bagian berikut di bawah ini.

'Arāfah merupakan kawah candradimuka untuk melahirkan pribadi ideal yang terpuji akhlaknya (Muhammad). Setelah wukuf di sini, diharapkan lahir Muhammad-muhammad baru yang ramah terhadap alam semesta, yakni orang-orang yang beroposisi dengan setan dan egonya. Mereka ini adalah kaum oposan dari antroposentris.

Saat di Mina, jamaah harus melakukan aksi yang dilakukan secara sadar, yakni melakukan kegiatan beroposisi dengan setan dan berkoalisi dengan Allah. Aksi tersebut diwujudkan dalam bentuk melempar jumrah sebanyak tiga tempat dan setiap tempat tujuh kali lemparan selama minimal tiga hari. Doa yang biasanya dibaca oleh jamaah adalah saat melempar jumrah, yakni rajman li al-syayātīin wa rị̣an li al-Rahmān, yang arti bebasnya adalah berposisi dengan setan dan rela berkoalisi dengan Dzat Yang Maha Pengasih.

Dalam analisis profetik, bahwa saat melakukan aksi lempar jumrah, manusia diminta oleh Allah untuk menjadi manusia sebagaimana fitrahnya. Dia (manusia) diciptakan memiliki keistimewaan dibanding makhluk lain (termasuk malaikat dan jin sekalipun) (Q.S.95:5). Hal ini karena itu, manusia harus mencoba menjadi manusia bukan kurang dan bukan lebih. Inilah humanisasi. Berkurangnya kadar kemanusiaan, menjadikan manusia akan terjat uh pada posisi hewan atau setan. Humanisasi yang tersirat dalam lempar jumrah di Mina mengisyaratkan agar manusia selalu memaksimalkan potensi yang telah diberikan oleh Allah padanya, yakni sebagaimana dalam Q.S.7:179.

Sementara itu, lempar jumrah juga syarat dengan perlawanan dan pembebasan dari sifat buruk dari dari dalam diri manusia (internal) maupun eksternal. Secara internal dia melempar egoisme, sifat ingin menang sendiri, dan arogansi. Sementara sifat buruk dari luar datang dari kejahat an yang dihembuskan oleh iblis sebagaimana janji iblis kepada Allah yang terekam dalam Q.S.38:82-83. Sementara itu, transendensinya lempar jumrah di Mina adalah proses penetapan diri sebagai hamba yang ingin mendapat ridha dari Allah (rị̣an li al-Raḥmān).

\section{E. Simpulan}

Visi profetik haji tampak mulai dari rukun pertama hingga terakhir. Sejak iḥrām sampai rukun terakhir tujuan akhir ibadah ini adalah membangun 
kemanusiaan sejati, yakni kualitas manusia sebagaimana fitrahnya. Manusia dititahkan Allah di bumi sebagai wakil (khalifah) Nya. Tugasnya adalah memakmurkan alam semesta.

Iḥrām mengajari manusia untuk melakukan proses ketawadhukan kepada makhluk seluruh alam. Sikap tawaḍu' dipantik melalui ritual haji. Ini dalam wacana profetik bemakna sebagai proses humanisasi. Tawadu' adalah sikap memuliakan manusia melalui sikap menghargai dan peduli. Tawaḍu dalam hal ini adalah proses humanisasi.

\section{Daftar Pustaka}

Aberry, A.J. 1993. Pasang Surut Aliran Tasawuf, Cet. IV. Bandung: Penerbit Mizan.

Ahimsa-Putra, Heidy. 2011. Paradigma Profetik (Makalah Seminar Tidak Diterbitkan). Yogyakarta: UGM.

al-Bukhārì. TT. Sahạịh al-Bukhārīi. Jilid 1. Ondisc Maktabah Syāmilah (CDROM). al-Qāhirah: Mawqi' Wazārah al-Awqāf.

Kuntowijoyo. 1994. Paradigma Islam. Bandung: Mizan.

Rahmena, Ali (Ed.). 1995. Para Perintis Zaman Baru Islam. Bandung: Mizan. Suwito NS. 2004. Transformasi Sosial; Kajian Epistemologis Pemikiran Islam Modern Ali Syari'ati. Purwokerto, Yogyakarta: STAIN Press dan Unggun Religi.

2011. Eko-Sufisme: Konsep, Implementasi, dan Dampak. Yogyakarta: Buku Litera.

Syari'ati, Ali. 1983. Haji. Bandung: Pustaka Hidayah.

1993. Membangun Masa Depan Islam. Bandung: Mizan. 